\title{
The application of geographic information systems (GIS) in the analysis of nutrient loadings from an agro-rural catchment
}

\author{
S Mtetwa ${ }^{1 *}$, S Kusangaya ${ }^{2}$ and CF Schutte ${ }^{1}$ \\ ${ }^{1}$ University of Pretoria, Department of Chemical Engineering, Pretoria 0002, Republic of South Africa \\ 2 University of Zimbabwe, Geography Department, PO Box MP 167, Mt Pleasant, Harare, Zimbabwe
}

\begin{abstract}
A large amount of data is usually generated during environmental monitoring programmes. The data need to be transformed into useful information that can be used for interpretation and analysis of problems. This paper outlines the feasibility of using geographic information system (GIS) techniques in the analysis of catchment nutrient yields with the aim of providing a knowledge base for effective decision-making. In this case the spatial and temporal distributions of the nutrient yields in the catchment were analysed. Interpolation with the GIS packages (Arc View Version 3.1 and Arc View Spatial Analyst) enabled the estimation of yields in areas without actual measurement thereof.
\end{abstract}

Key words: GIS, nutrient yields, ACRU, pollution loads, spatial distribution.

\section{Introduction}

The objective of the project on which this paper is based, is to develop a methodology for managing the water quality in the rural areas of developing semi-arid regions. The water quality problems experienced in these areas are mostly of a diffuse nature and their control is difficult. The major problems in the rural areas include overgrazing, siltation, poor agricultural practices and poor land management, emanating from technological, economical and sociopolitical problems with numerous stakeholders who have differing goals and perceptions (Fedra, 1984, Ongley, 1998). This paper follows on an earlier paper (Mtetwa and Schutte, 2002) in which details of the Muda catchment, farming practices and pollution loads are given. Here the focus is on the feasibility of using a geographical information system (GIS) in the analysis of water quality data to facilitate decision-making.

GIS can be defined as (ESRI 1996): An organised collection of computer hardware, software, geographic data, and personnel designed to efficiently capture, store, update, manipulate, analyse, and display all forms of geographically referenced information. GIS technology integrates common database operations such as query and statistical analyses with the unique visualisation and geographic analysis benefits offered by maps and spatial databases. These abilities distinguish GIS from other information systems and make it a valuable tool for explaining events, predicting outcomes, and planning strategies.

\footnotetext{
* To whom all correspondence should be addressed. Current address: Zimbabwe National Water Authority, Water Quality Section, PO Box CY 617, Causeway, Harare, Zimbabwe.

푱+263 4 793139; fax: +2634 793139;

e-mail: mtetwa@utande.co.zw

Received 4 April 2002; accepted in revised form

28 Jапиагу 2003
}

\section{Procedures and analyses}

A key parameter required in the development of water quality management methodologies is the nutrient loads emanating from catchment and subcatchments. These loads form the basis of any decisions on the management actions to be taken to preserve water quality. Nutrient loads were derived from the product of the nutrient concentrations and their corresponding discharges as described below.

\section{Water quality}

Water quality data are not readily available in developing countries, and a water quality monitoring programme had to be implemented to obtain the required information. A total of 10 sampling sites were established as is shown in Fig. 1. Water quality samples

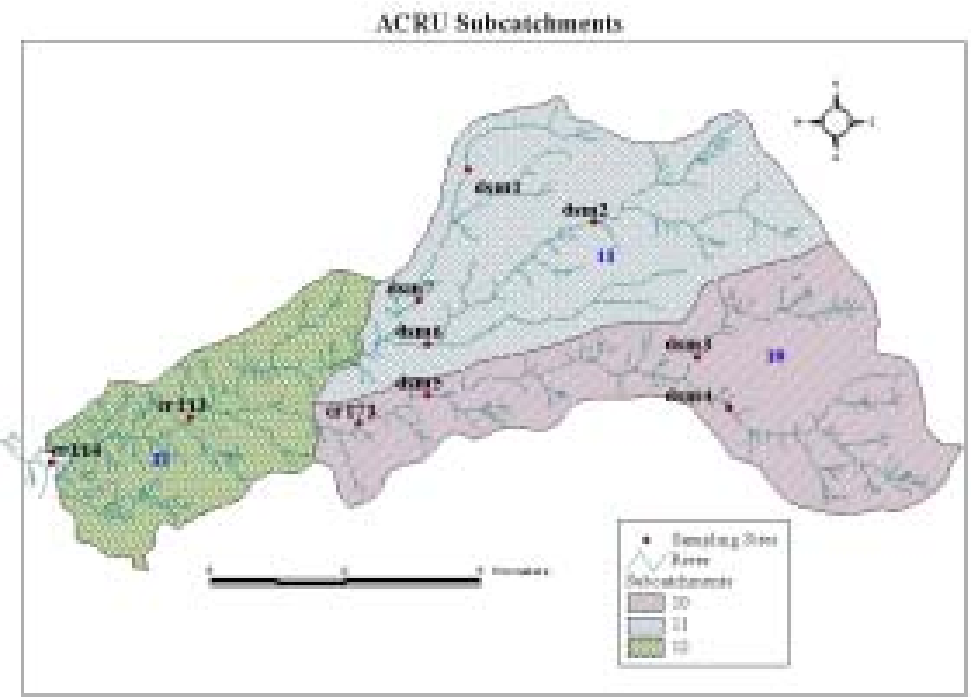

Figure 1

Muda River subcatchments and sampling sites 


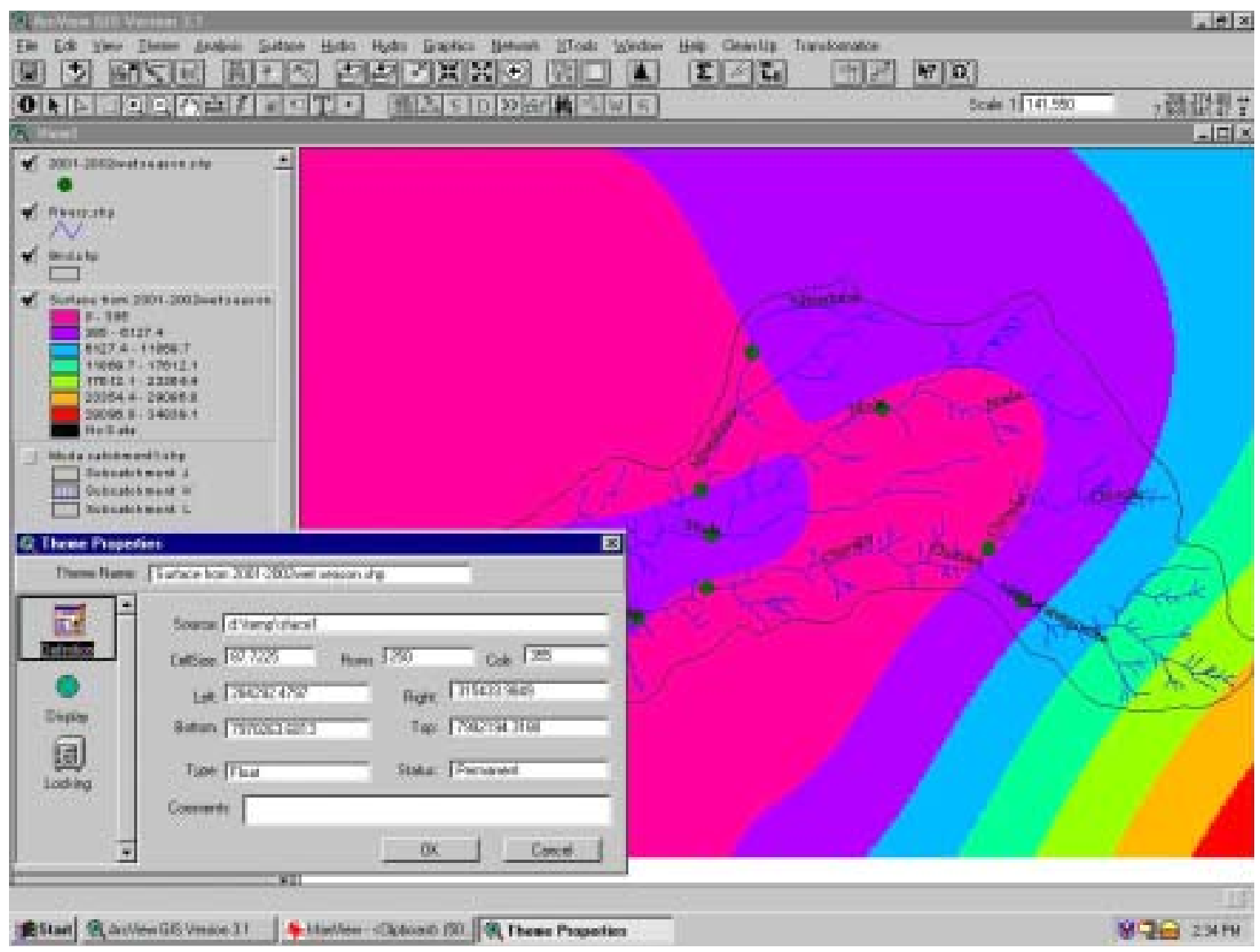

Figure 2

Sample input points and the output grid theme from the interpolation

were collected from these sites on a weekly basis and analysed for a number of parameters including nitrate and phosphate. The nitrates and phosphates were analysed using spectrophotometric methods. The weekly nutrient concentrations were averaged to give monthly time steps for the purposes of this study.

\section{ACRU discharge estimation}

Flow data are not readily available and had to be generated from rainfall data using the ACRU runoff model (Schulze, 1995). The ACRU agro-hydrological modelling system is a physical conceptual model that can be used for various aspects such as water resource assessment, irrigation water demand and supply evaluation, shallow groundwater modelling and assessments of landcover and land management changes on water resources. It is based on physically measurable or derivable catchment characteristics.

For the purpose of the simulations, the Muda River catchment was subdivided into three subcatchment areas using land-cover information obtained from Landsat TM image of 26 April 1998 (Fig.1). This was done through on-screen digitising (using ArcView Version 3.1) after identifying homogenous land classes from the image. For each subcatchment information on the catchment area, location, altitude, catchment configuration, daily rainfall, mean monthly evaporation, minimum and maximum temperature, landcover, soil texture, soil depth and wind speed were input into the model so as to derive streamflow data over a period of three years. Most of the input data were obtained from an automatic weather station at Mahusekwa, a growth point in the study area. The discharge obtained from the simulations represents the discharge that could be obtained at the end of each subcatchment.

The ACRU model provides a quantitative (i.e. mathematical) expression of the observation, analysis and prediction of the timevariant interactions of these agro-hydrological parameters. The outputs are then used in the planning, design and management/ operation of agro-hydrologically related systems and structures (Schulze, 1995). The accuracy of simulation depends on three factors - accuracy of input data, effectiveness of parameter evaluation, and inherent errors in the model (Linsley et al., 1986).

\section{Nutrient yield analysis}

The major nutrients likely to arise from fertiliser applications in both the communal areas and the small-scale commercial farms are phosphates and nitrates. Suspended solids were also determined since they arise from the farming activities in these areas and are reported elsewhere (Mtetwa and Schutte, 2002). Nutrient loads, obtained by multiplying the nutrient concentration and the corresponding discharge were input into the attribute tables of the point map of the sampling sites for analysis.

Spatial analysis was done using the ArcView Spatial Analyst Extension. The Spatial Analyst presents generic spatial analysis functionality on grid and feature themes that is added to ArcView as an extension. Among other functionalities the Spatial Analyst Extension enables the following operations to be carried out: establishing distance, assigning proximity, calculating density, calculating cell statistics, map querying, neighbourhood statistics, 


\section{Dry Season 2000 Nitrate Loads}

Figure 3 Nitrates loads for 2000 (dry season)

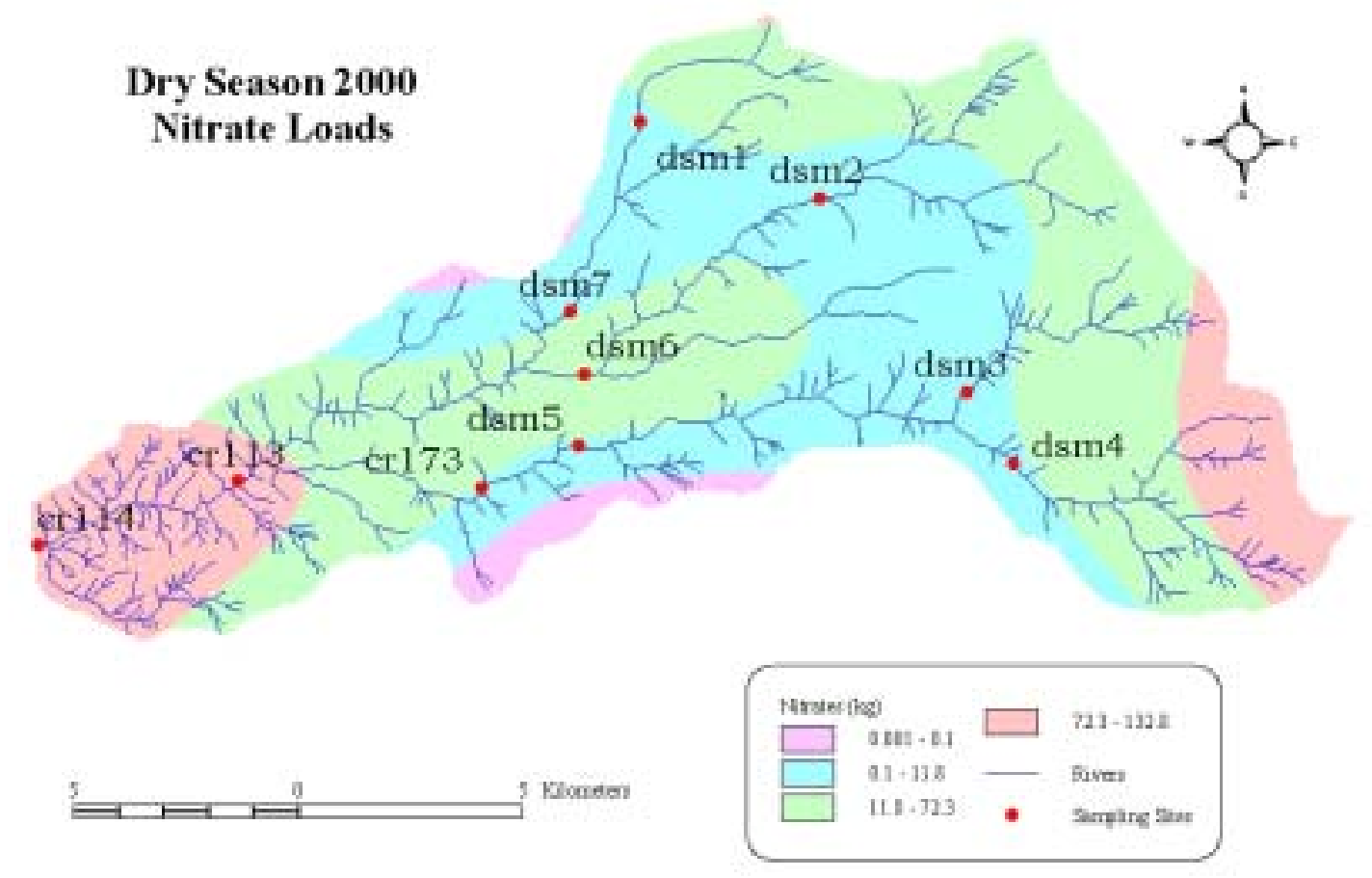

reclassifying, interpolating grid, deriving slope, computing hill shading and converting to grid. The ArcView 3.1 and ArcView Spatial Analyst are to be replaced by the Arcview 8 series, ArcGIS Spatial Analyst and ArcGIS Geostatistical Analyst.

The following procedure was used in the interpolation of the nutrient loads to obtain the spatial distribution:

- A point map of the sampling sites was created, the attributes of which constituted all the average nutrient concentrations of concern, as well as the corresponding discharges per the given times.

- The average nutrient concentrations were then multiplied by the average discharge per the given times to give the nutrient loads that were used in the interpolation.

\section{Interpolation}

- Activate ArcView Spatial Analyst.

- Click on the point theme to make it active.

- From the surface menu choose Interpolate Grid.

- Specify the output grid extent and the output grid cell size (and if necessary the number of rows and number of columns) in the output grid specification dialog, which appears.

- On the interpolation dialog, set the method to spline and the ZValue to nutrient load under consideration.

- Click OK (and a new grid theme will be drawn on the view),

- On the theme menu go to save as, or convert to grid to save the new grid theme using an appropriate grid name as, e.g. phosphate loads.

The above was done for both the wet and the dry seasons.

\section{Why the spline option?}

Visiting every location in a study area to measure the height, magnitude, or concentration of a phenomenon is usually difficult or expensive. Instead, dispersed sample input point locations were selected strategically and surface interpolation was used to assign an estimated value to all other locations (ESRI, 1996). Input points can be either randomly or regularly spaced points containing height, concentration, or magnitude measurements (Fig. 2).

The Spline interpolator is a general-purpose interpolation method that fits a minimum-curvature surface through the input points (ESRI, 1996). It fits a mathematical function to a specified number of nearest input points, while passing through the sample points. This method is best for gently varying surfaces such as elevation, water table heights, or pollution concentrations. It is not appropriate if there are large changes in the surface within a short horizontal distance, because it can overshoot estimated values. The Regularised method yields a smooth surface. The Tension method tunes the stiffness of the surface according to the character of the modelled phenomenon. The weight parameter defines the weight of the third derivatives of the surface in the curvature minimisation expression. The number of points per parameter identifies the number of points per region used for local approximation.

The grid data set associated with the output theme is written to the project's working directory (Fig. 2). Properties in the Theme menu are used to determine which data set is associated with which theme. Properties in the Project menu are used to change the project's working directory. The grid data set associated with the output theme is temporary and Save Data Set in the Theme menu is used to save the data.

\section{Spatial distributions}

Spatial distributions of nitrates and phosphates for both the rainy and dry seasons were computed. The 2000 and 2001 seasons are used to illustrate the findings, the dry season being from April to September and the wet season being from October to March:

\section{Nitrate loads spatial distribution}

Generally there is an increase in the nitrate load from the upper catchment towards the lower catchment areas and the epicentre of the highest concentrations generally shifts towards the exit of the catchment in the wet season. 


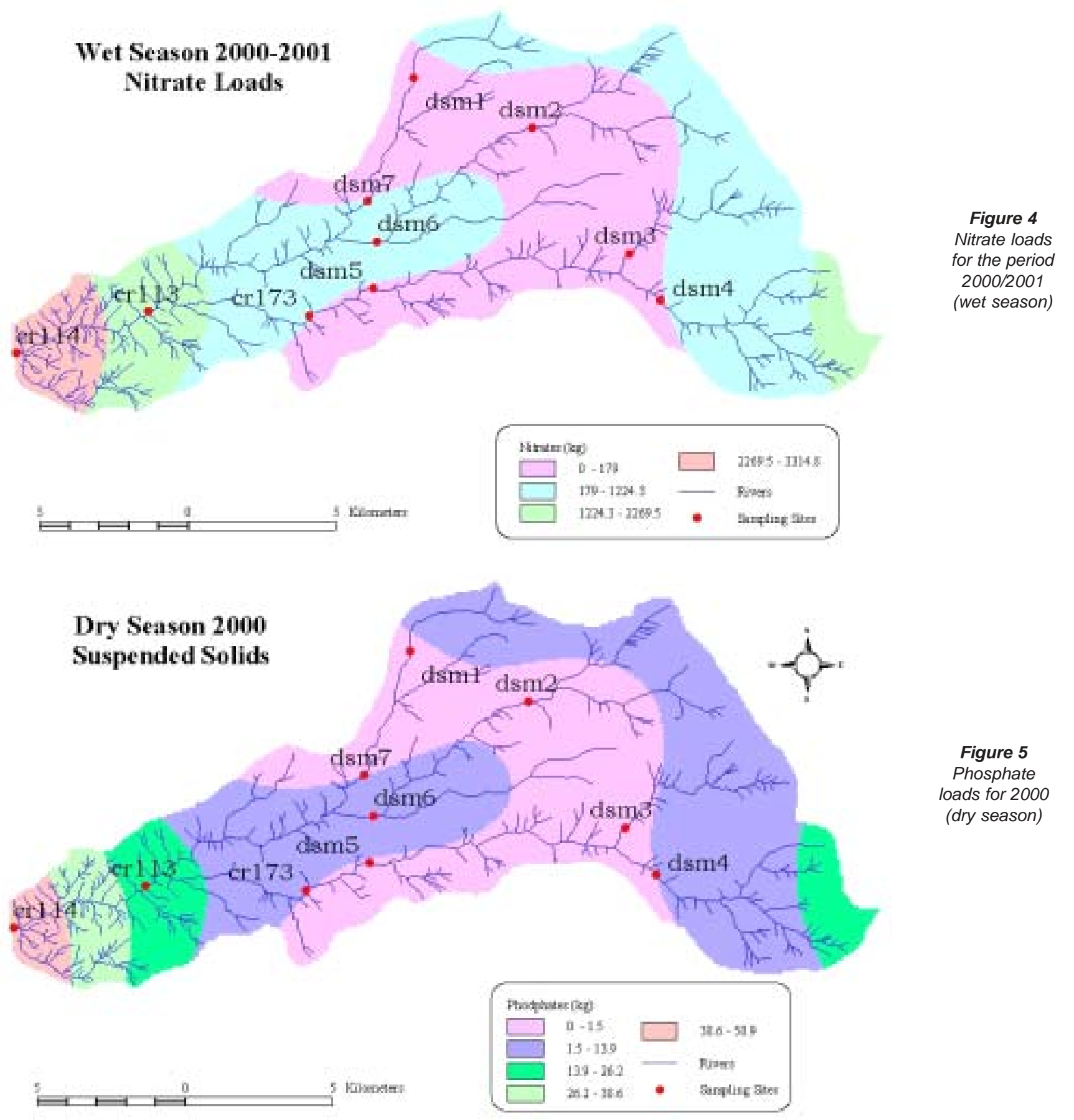

\section{Phosphate loads spatial distributions}

The phosphate loads follow more or less the same pattern as the nitrate loads.

The shift in the epicentres on moving from the dry season to the wet season is a result of the fact that most of the market gardening is carried out around the middle of the catchment. A further factor is that during the dry season the flows are mostly too low to carry the pollutants downstream.

As expected, phosphate and nitrate loads are lower in the dry season ranging from 0 to $72.3 \mathrm{~kg}$ (nitrates) and 0 to $38.6 \mathrm{~kg}$ (phosphates) and the rainy season loads range from 0 to $2269.5 \mathrm{~kg}$ (nitrates) and 0 to 182.4 (phosphates). This is basically explained by the pronounced reduced discharge in the dry season and subsequent drying-up of most of the smaller tributaries especially in the upper catchment.

\section{Conclusion}

Water quality has to be considered within the spatial context within which it occurs. Water quality parameters are generally measured at specific sampling points and reflect the influence of the upstream environment (Cobban and Silberbauer, 1993). In the current study geographic information systems have been used to present the measured and calculated data in a summarised form from which trends can be discerned. This can be used in predictive and anticipatory management decisions, especially where changes in water quality are linked to changes in land-use activities. 


\section{Wet Season 2000-2001 Phosphate Loads}

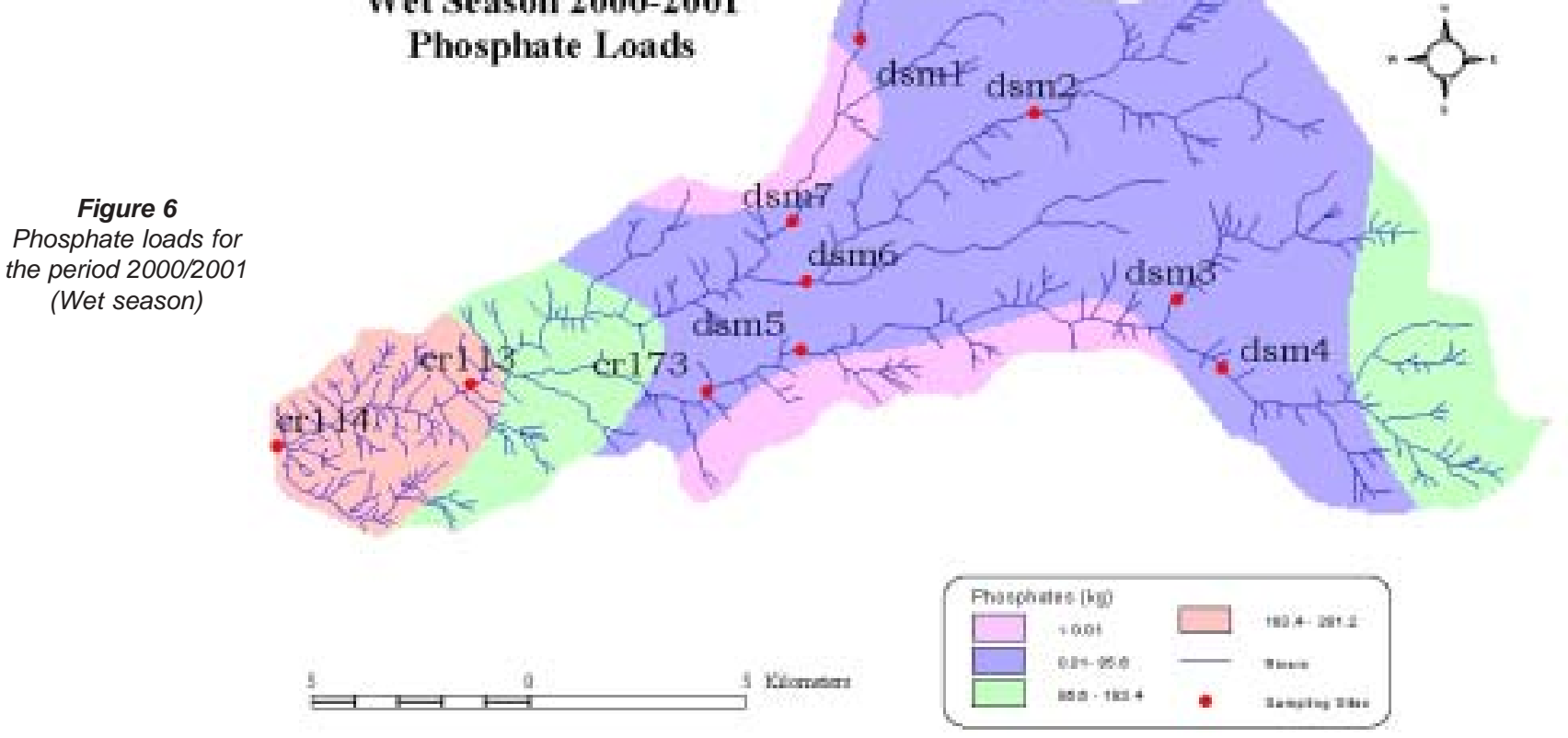

It is also important to note that nutrient yields of rivers are dependent on a complex interaction between soil characteristics and agricultural practices within the catchment and with flow rates of the streams draining the catchment (Zimmer and Bendoricchio, 2001).

In the current study, the lower catchment, which mainly comprises the small-scale commercial farms, is characterised by lower loads than the communal areas in the upper catchment during the dry season but exhibits high levels in the wet season. This is a reflection of the land-use patterns.

From the spatial analysis potential problem areas can be identified during the two seasons and appropriate decisions can be made to minimise pollutant discharges. Catchment rehabilitation can therefore be focused on areas with high pollutant generation and periods when pollutant flushes are highest.

\section{References}

COBBAN DA and SILBERBAUER MJ (1993) Water quality decision making facilitated through the development of an interface between a geographic information system and a water quality database. Proc. 6th
S. Afr. Natl. Hydrol. Symp., Univ. of Natal, Pietermaritzburg, South Africa.

ENVIRONMENTAL SYSTEMS RESEARCHINSTITUTE(ESRI) (1996) ArcView Spatial Analyst, Advanced Spatial Analysis using Raster and Vector Data, NY.

FEDRA K (1984) Interactive water quality simulation in a regional framework: A management oriented approach to lake and watershed modelling, Ecol. Modelling 21 209-32.

LINSLEY RK (Jr.), KOHLER MA and PAULHUS H (1986) Hydrology for Engineers ( $3^{\text {rd }}$ edn.), McGraw-Hill, Inc, USA.

MTETWA S and SCHUTTE CF (2002) An interactive and participative approach to water quality management in agro-rural watersheds. Water SA 28 (3).

ONGLEY ED (1998) Modernisation of water quality programmes in developing countries: Issues of relevancy and cost efficiency. Water Qual. Int. (September/October).

SCHULZE RE (1995) Hydrology and Agrohydrology: A Text to Accompany the ACRU 3.00 Agrohydrological Modelling System. Water Research Commission, Pretoria, Report TT69/95.

ZIMMER V and BENDORICCHIO G (2001) Nutrient and suspended solid loads in the Laguna de Bay, Philippines. Water Sci. Technol. 44 (7) $77-86$. 